\title{
Utilization of Ion Exchangers in Analytical Chemistry
}

\author{
XXIX. Sorption and Elution of Some Low-Molecular-Weight \\ Organic Acids
}

\author{
SVANTE BERNTSSON and OLOF SAMUELSON
}

Department of Engineering Chemistry, Chalmers Tekniska Högskola, Göteborg, Sweden

\begin{abstract}
The sorption and elution of glycolic, oxalic, pyruvic, gluconic, maleic, and $p$-toluenesulfonic acids using the strongly basic resin Dowex 2 (acetate form) and the weakly basic resin Dowex 3 (freebase form) have been studied. All acids except gluconic acid can be taken up quantitatively by the resins.

Glycolic, oxalic, gluconic, and maleic acids can be quantitatively displaced from both types of resins by means of sulfuric acid or ammonium carbonate. From the strongly basic resin, pyruvic acid can be displaced quantitatively only by means of acid elutriants. The elution of this acid from the weakly basic resin is in no case quantitative. Hydrochloric acid is the most effective elutriant for $p$-toluenesulfonic acid when the strongly basic resin is concerned, whereas the weakly basic resin is most easily regenerated with sodium hydroxide.
\end{abstract}

Several authors have used anion exchange resins for the isolation of organic acids. The results are summarized in Samuelson's monograph ${ }^{1}$. This topic has also been studied in some more recent papers ${ }^{2-6}$. The uptake of the acids does not seem to have caused any troubles whereas in some cases it has been reported that the recovery in the elution step is incomplete. Most authors have been interested in the chromatographic separation of different acids from each other. Very little attention has been given to the question of whether the recovery in the regeneration step can, from an analytical point of view, be considered as quantitative. For this reason it seemed to be appropriate to study in greater detail the uptake and especially the elution of different types of organic acids.

\section{EXPERIMENTAL TECHNIQUE}

Ion Exchange Column. The ion exchange column was of common construction (Ref.1, Fig. 23). The diameter and length of the resin bed were $9 \mathrm{~mm}$ and $170 \mathrm{~mm}$. The resin had the particle size $0.20-0.30 \mathrm{~mm}$ in an air-dry condition. The acetate form of the resin was prepared by passing $400 \mathrm{ml} M$ sodium acetate solution through the column and sub-

Acta Chem. Scand. 9 (1955) No. 2 
sequent washing with water. In order to transform the resin into the free-base form it was instead treated with the same amount of $M$ sodium hydroxide solution, preceutions being taken to exclude carbon dioxide. Dowex 2 was regenerated according to the ordinary column technique whereas the regeneration of Dowex 3 was achieved by a combined batch and column operation to avoid channeling due to the swelling of the resin. Fifty $\mathrm{ml}$ of the elutriant was placed in the funnel attached to the column. After placing a stopper in the upper end of the funnel the column was shaken in order to transfer the resin into the funnel. The resin was then allowed to settle in the column and the elutriant passed through.

The resins are not quite stable in water and interference occurred because of dissolution of resin material. In order to eliminate as far as possible this source of error the resin was conditioned with $500 \mathrm{ml} M$ sodium hydroxide solution and afterwards with $500 \mathrm{ml}$ of the elutriant. The conditioning was repeated several times.

In all experiments the added amount of acid was about 2 meq and the flow rate about $2 \mathrm{ml} / \mathrm{min}$. All figures given in the tables are expressed in per cent of the added amount.

Determination of the Acids. Glycolic, gluconic, and maleic acids were determined by oxidation with dichromate in sulfuric acid solution according to the following scheme.

$$
\begin{aligned}
& \mathrm{C}_{2} \mathrm{H}_{4} \mathrm{O}_{2}+3 \mathrm{O} \\
& \mathrm{C}_{6} \mathrm{H}_{12} \mathrm{O}_{2}+11 \mathrm{O} \\
& \mathrm{C}_{4} \mathrm{H}_{4} \mathrm{O}_{4}+6 \mathrm{O}
\end{aligned} \longrightarrow \begin{aligned}
& 2 \mathrm{CO}_{2}+2 \mathrm{H}_{2} \mathrm{O} \\
& \mathrm{CO}_{2}+6 \mathrm{H}_{2} \mathrm{O} \\
& 4 \mathrm{CO}_{2}+2 \underset{\mathrm{H}_{2} \mathrm{O}}{ }
\end{aligned}
$$

The equivalent weights of glycolic, gluconic, and maleic acids are 1/6, 1/22 and $1 / 12$ of the molecular weights, respectively.

The acid was introduced into a 1-liter flask and $0.5 \mathrm{~N} \mathrm{~K}_{2} \mathrm{Cr}_{2} \mathrm{O}_{7}$-solution, to an excess of at least $1 \mathrm{meq}$, was added from a micro-buret. After addition of water to $60 \mathrm{ml}$ volume, $100 \mathrm{ml}$ conc. sulfuric acid was added under shaking. The flask was allowed to stand for $30 \mathrm{~min}$ and then cooled. After adding $500 \mathrm{ml}$ distilled water, the flask was again cooled to room temperature. The excess potassium dichromate was determined in the usual manner by adding potassium iodide and titrating with sodium thiosulfete. In control experiments with the pure acids, the error was in all cases less than $0.5 \%$.

Oxalic acid was determined by oxidation with permanganate. Pyruvic acid was analyzed according to a colorimetric method ?. $p$-Toluenesulfonic acid was determined spectrophotometrically in ultraviolet at $260 \mathrm{~m} \mu$. The spectrophotometric readings were made with a Beckman spectrophotometer model DU.

Blank experiments were run in order to obtain a correction for the dissolution of organic matters from the resin. The correction was in no case greater than $2 \%$.

\section{RESULTS}

The experiments with glycolic, oxalic, pyruvic, maleic, and $p$-toluenesulfonic acids show that all these acids can be taken up quantitatively by the acetate form of a strongly basic resin and by the free-base form of a weakly basic resin. The uptake of gluconic acid is incomplete with both types of resin. The amount of acid which passes through the column is indicated under the Tables 1 and 2 . The fact that gluconic acid is not retained quantitatively is explained by the presence of lactones.

The results presented in Tables 1 and 2 show that glycolic, oxalic, gluconic, and maleic acids can be easily displaced from both types of resins by means of $0.5 M$ sulfuric acid or $0.5 M$ ammonium carbonate solutions. As can be seen from Table 3, oxalic acid is eluted with $150 \mathrm{ml}$ of $M \mathrm{HCl}, 0.5 M \mathrm{H}_{2} \mathrm{SO}_{4}, 0.5 M$ $\left(\mathrm{NH}_{4}\right)_{2} \mathrm{SO}_{4}, 0.5 M\left(\mathrm{NH}_{4}\right)_{2} \mathrm{CO}_{3}$, or $M \mathrm{NaOH}$.

The behavior of pyruvic and $p$-toluenesulfonic acids is much more complicated. Table 4 shows that pyruvic acid is recovered quantitatively from the strongly basic resin with hydrochloric acid or sulfuric acid, whereas unsatis- 
Table 1. Elution of acids from the strongly basic resin Dowex 2 (acetate form).

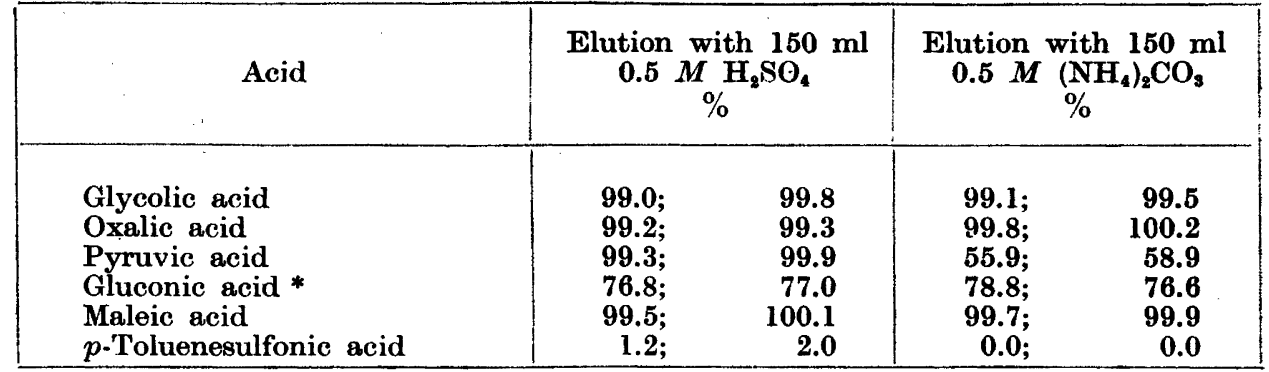

* The amount of gluconic acid in the effluent from the sorption step was 22.8, 23.0, 23.1, and $23.1 \%$ respectively.

Table 2. Elution of acids from the weakly basic resin Dowex 3 (free-base form).

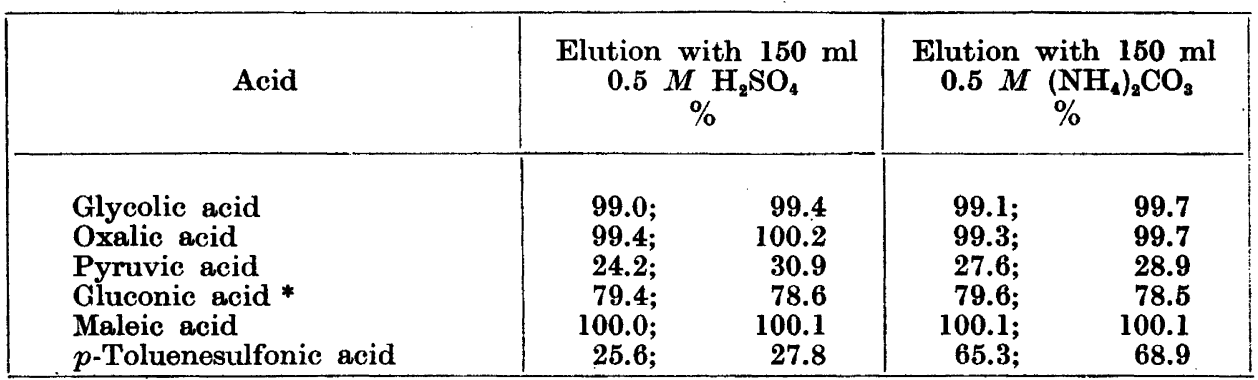

* The amount of gluconic acid in the effluent from the sorption step was $20.1,20.7,20.1$, and $20.6 \%$ respectively.

Table 3. Elution of oxalic acid from the strongly basic resin Dowex 2 (acetate form) and the weakly basic resin Dowex 3 (free-base form) with $150 \mathrm{ml}$ of different elutriants.

\begin{tabular}{|c|c|c|c|c|}
\hline Elutriant & \multicolumn{2}{|c|}{$\begin{array}{c}\text { Elution from } \\
\text { Dowex } 2 \\
\%\end{array}$} & \multicolumn{2}{|c|}{$\begin{array}{c}\text { Elution from } \\
\text { Dowex } 3 \\
\%\end{array}$} \\
\hline 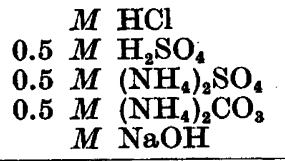 & $\begin{array}{r}99.4 ; \\
99.4 ; \\
99.7 ; \\
99.8 ; \\
100.1 ;\end{array}$ & $\begin{array}{r}100.0 \\
99.3 \\
99.9 \\
100.2 \\
100.1 \\
\end{array}$ & $\begin{array}{r}99.7 \\
99.4 ; \\
100.0 ; \\
99.6 ; \\
99.8 ;\end{array}$ & $\begin{array}{r}100.3 \\
100.2 \\
100.1 \\
99.7 \\
100.1\end{array}$ \\
\hline
\end{tabular}

factory results are obtained with the other elutriants. From the free-base form of the weakly basic resin, pyruvic acid can be removed only to a limited extent even when large quantities and high concentrations of the elutriants are used.

Acta Chem. Scand. 9 (1955) No. 2 
Table 4.: Elution of pyruvic acid from the strongly basic resin Dowex 2 (acetate form) and the weakly basic resin Dowex 3 (free-base form).

\begin{tabular}{|c|c|c|c|c|}
\hline Elutriant & \multicolumn{2}{|c|}{$\begin{array}{c}\text { Elution from } \\
\text { Dowex } 2 \\
\%\end{array}$} & \multicolumn{2}{|c|}{$\begin{array}{c}\text { Elution from } \\
\text { Dowex } 3 \\
\%\end{array}$} \\
\hline 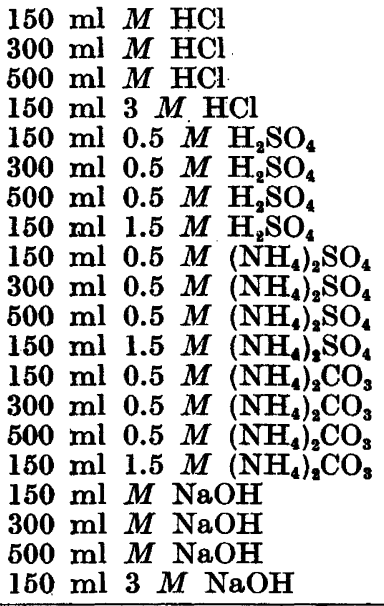 & $\begin{array}{l}\text { 91.0; } \\
88.9 ; \\
89.0 ; \\
86.4 ; \\
55.9 ; \\
63.0 ; \\
68.3 ; \\
32.7 ; \\
82.7 ; \\
84.6 ; \\
85.0 ; \\
63.0 ;\end{array}$ & $\begin{array}{l}94.8 \\
89.7 \\
89.9 \\
90.6 \\
58.9 \\
64.6 \\
70.9 \\
35.4 \\
84.6 \\
86.6 \\
86.4 \\
66.9\end{array}$ & $\begin{array}{l}29.1 ; \\
20.7 ; \\
35.0 ; \\
24.6 ; \\
24.4 ; \\
21.7 ; \\
32.9 ; \\
26.4 ; \\
23.6 ; \\
23.8 ; \\
30.5 ; \\
9.4 ; \\
27.6 ; \\
17.7 ; \\
33.7 ; \\
16.5 ; \\
21.1 ; \\
27.0 ; \\
39.4 ; \\
14.8 ;\end{array}$ & $\begin{array}{l}34.3 \\
29.5 \\
36.8 \\
26.4 \\
30.9 \\
24.6 \\
35.0 \\
26.4 \\
26.0 \\
24.6 \\
32.3 \\
12.4 \\
28.9 \\
24.6 \\
36.4 \\
19.7 \\
30.9 \\
27.0 \\
40.6 \\
20.7\end{array}$ \\
\hline
\end{tabular}

In separate experiments it was observed that the strongly basic resin, used for the uptake of pyruvic acid and subsequently treated with ammonium sulfate, could not be regenerated with hydrochloric acid. No traces of pyruvic

Table 5. Elution of p-toluenesulfonic acid from the strongly basic resin Dowex 2 (acetate form) and the weakly basic resin Dowex 3 (free-base form).

\begin{tabular}{|c|c|c|c|c|}
\hline Elutriant & \multicolumn{2}{|c|}{$\begin{array}{c}\text { Elution from } \\
\text { Dowex } 2 \\
\%\end{array}$} & \multicolumn{2}{|c|}{$\begin{array}{c}\text { Elution from } \\
\text { Dowex } 3 \\
\%\end{array}$} \\
\hline 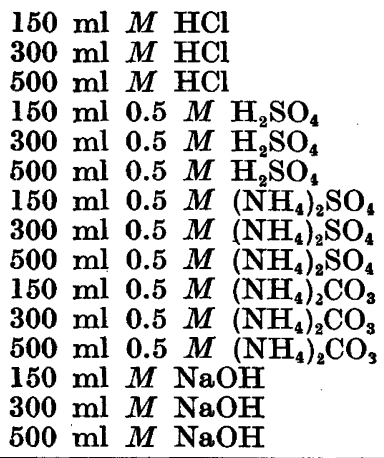 & $\begin{array}{r}0.8 ; \\
32.4 ; \\
70.1 ; \\
1.2 ; \\
10.1 ; \\
40.5 ; \\
0.0 ; \\
0.0 ; \\
0.0 ; \\
0.0 ; \\
0.0 ; \\
0.0 ; \\
0.6 ; \\
7.3 ; \\
29.3 ;\end{array}$ & $\begin{array}{r}2.2 \\
33.8 \\
72.8 \\
2.0 \\
11.4 \\
41.3 \\
0.0 \\
0.0 \\
0.0 \\
0.0 \\
0.0 \\
0.0 \\
1.4 \\
9.2 \\
30.6\end{array}$ & $\begin{array}{l}21.9 ; \\
44.4 ; \\
71.3 ; \\
25.6 ; \\
44.0 ; \\
62.0 ; \\
25.7 ; \\
35.8 ; \\
44.6 ; \\
65.3 ; \\
76.3 ; \\
82.9 ; \\
94.9 ; \\
99.9 ;\end{array}$ & $\begin{array}{r}24.1 \\
46.8 \\
72.9 \\
27.8 \\
45.0 \\
63.6 \\
29.1 \\
36.6 \\
45.5 \\
68.9 \\
79.4 \\
86.8 \\
98.6 \\
100.0 \\
\end{array}$ \\
\hline
\end{tabular}


Table 6. Elution of p-toluenesulfonic acid from the strongly basic resin Dowex 2 (acetate form I with $250 \mathrm{ml}$ hydrochloric acid of different concentration.

\begin{tabular}{|c|c|}
\hline $\begin{array}{c}\text { Elutriant } \\
\text { concentration }\end{array}$ & $\underset{\%}{\text { Elution }}$ \\
\hline $\begin{array}{ll}1 & M \\
2 & M \\
3 & M \\
4 & M \\
6 & M \\
\end{array}$ & $\begin{array}{l}39.3 \\
61.6 \\
81.5 \\
83.4 \\
81.3\end{array}$ \\
\hline
\end{tabular}

acid could be detected in the effluent from the regeneration step when the solution was investigated by the colorimetric method. Similar experiments in which the resin was treated with ammonium carbonate or sodium hydroxide instead of ammonium sulfate gave the same results. In some experiments with pyruvic acid, the determinations were made by an alkalimetric titration. The results indicate that the incomplete recovery of pyruvic acid is due to a decomposition of the acid during the ion exchange cycle.

The data given in Table 5 show that, for the elution of $p$-toluenesulfonic acid from the strongly basic resin, hydrochloric acid is more effective than sulfuric acid and sodium hydroxide. It is interesting to note that no traces of the acid have been detected in the effluent after treatment with large amounts of ammonium sulfate and ammonium carbonate solutions in the elution step. The influence of the strength of hydrochloric acid used as elutriant for $p$-toluenesulfonic acid has been studied. The results are given in Table 6. As can be seen from the table, $3 M$ hydrochloric acid is an effective elutriant. As a complement to the data presented in the tables two elutions with $500 \mathrm{ml} 3 M$ hydrochloric acid were performed. The recovery was $100.0 \%$ in both experiments.

From the weakly basic resin, $p$-toluenesulfonic acid is eluted quantitatively by means of sodium hydroxide solution (Table 5). The other elutriants investigated are less effective and are unsatisfactory for practical use.

Separate experiments show that $p$-toluenesulfonic acid is not fixed in an irreversible manner by any of the elutriants used in the present investigation. After the passage of $150 \mathrm{ml}$ of the elutriants giving an incomplete elution from the strongly basic resin, a quantitative displacement is achieved on subsequent treatment with $500 \mathrm{ml} 3 \mathrm{M}$ hydrochloric acid. In similar experiments with the weakly basic resin a complete recovery is obtained by final displacement with $300 \mathrm{ml} M$ sodium hydroxide.

As already mentioned gluconic acid is not taken up quantitatively under the conditions used in the experiments described above. A quantitative uptake of gluconic acid can be achieved by passing a solution of the sodium salt through a column filled with a strongly basic resin in the acetate form. From an acid solution, gluconic acid can be conveniently taken up by shaking the solution with an excess of the free-base form of the weakly basic resin for $24 \mathrm{~h}$. The acid can then be eluted completely with $150 \mathrm{ml} 0.5 \mathrm{M} \mathrm{H}_{2} \mathrm{SO}_{4}$ from both the strongly basic and the weakly basic resin. 
The State Technical Research Council (Statens Tekniska Forskningsråd) has supported the research financially, which support is gratefully acknowledged.

\section{REFERENCES}

1. Samuelson, O. Ion Exchangers in Analytical Chemistry, New York, John Wiley and Sons, 1953 and Stockholm, Almqvist and Wiksell, 1952.

2. Busch, H., Hurlbert, R. B. and Potter, R. V. J. Biol. Chem. 196 (1952) 717.

3. Bryant, F. and Overall, B. T. Biochim. et Biophys. Acta 10 (1953) 471.

4. Khym, Z. X. and Doherty, D. G. J. Am. Chem. Soc. 74 (1952) 3199.

5. Owens, H. S., Goodban, A. E. and Stark, J. B. Anal. Chem. 25 (1953) 1507.

6. Schenker, H. and Rieman III, W. Anal. Chem. 25 (1953) 1637.

7. Berntsson, S. To be published.

Received November 26, 1954. 